\title{
Determination of the activation energies of phase transition for calcium orthophosphates based on powder X-ray diffraction data
}

Kateryna Vasylenko

Ukrainian State University of Chemical Technology

\section{Yuriy Sakhno}

University of Delaware

Deb Jaisi

University of Delaware

Mykola Nikolenko ( $\square$ n_nikolenko@ukr.net)

Ukrainian State University of Chemical Technology

\section{Research Article}

Keywords: X-ray powder diffraction analysis, calcium orthophosphates, activation energies

Posted Date: May 19th, 2021

DOI: https://doi.org/10.21203/rs.3.rs-506356/v1

License: (9) This work is licensed under a Creative Commons Attribution 4.0 International License. Read Full License

Version of Record: A version of this preprint was published at Crystal Research and Technology on December 17th, 2021. See the published version at https://doi.org/10.1002/crat.202100215. 


\title{
Determination of the activation energies of phase transition for calcium orthophosphates based on powder X-ray diffraction data
}

\author{
Kateryna Vasylenko1, Yuriy Sakhno²; Deb Jaisi²; Mykola Nikolenko1,,
}

${ }^{1}$ Faculty of Chemical Technologies and Ecology, Ukrainian State University of Chemical Technology, Dnipro, 49005, Ukraine

${ }^{2}$ Department of Plant and Soil Sciences, University of Delaware, Newark, DE, 19716, USA

*Corresponding author: Nikolenko N. Email: $\underline{n \_n i k o l e n k o @ u k r . n e t}$, 


\section{ABSTRACT}

Kinetic studies of the transformation of calcium orthophosphates metastable precipitates were performed under different synthesis conditions. Phase composition and degree of crystallinity were investigated by X-ray powder diffraction analysis. In acidic solution, precipitates of $\mathrm{CaHPO}_{4} \cdot 2 \mathrm{H}_{2} \mathrm{O}$ (DCPD) and $\mathrm{CaHPO}_{4}$ (DCPA) are formed at the early stage of precipitation, with the degree of crystallinity at the range of 17-35\%. Specifically,

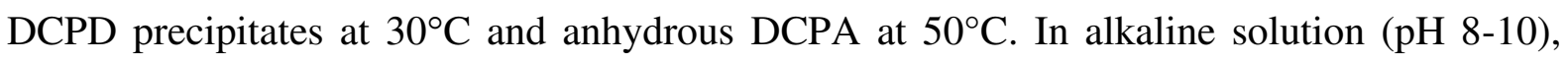
only amorphous forms of calcium orthophosphate is precipitated, which is explained by the high degree of supersaturation (i.e., the high rate of precipitation compared to that in acidic media). The diffraction peaks of DCPD and DCPA are found to be 0.3-0.45 degrees lower relative to their reference data, which is caused by decrease of lattice strain during early stage of crystallization. Furthermore, the initial molar ratio of $\mathrm{Ca} / \mathrm{P}$ in reagent mixture was found to play subordinary role in determining the composition of final calcium phosphate precipitates. The effect of $\mathrm{pH}$ on the composition of precipitates is illustrated by the solubility isotherms of pure calcium orthophosphates. Given that the intensities of diffraction peaks are proportional to planar density of the material in the given plane, we propose, for the first time, to determine activation energy of phase transformation of calcium orthophosphate from $\mathrm{X}$-ray powder diffraction patterns. Based on this relationship developed, the activation energy for the recrystallization DCPD and DCPA are 10.2 and $13.1 \mathrm{~kJ} / \mathrm{mol}$, respectively and for the phase transition of DCPD to DCPA - $36.7 \mathrm{~kJ} / \mathrm{mol}$. Further recrystallization to most thermodynamically stable $\mathrm{Ca}_{10}\left(\mathrm{PO}_{4}\right)_{6}(\mathrm{OH})_{2}$ hydroxyapatite (HA) occurs at the activation energy of $5.2 \mathrm{~kJ} / \mathrm{mol}$. These findings are critical on phase transition and transformation of calcium phosphate minerals.

\section{Introduction}

Among inorganic compounds of calcium and phosphorus, calcium orthophosphates are of particular interest. They are the mineral basis of bone tissue and are therefore considered as promising biomaterials. They are actively used in modern plastic surgery and medical cosmetology. ${ }^{1-3}$ For example, one of the most common procedures in cosmetology today is contouring, the filler of which includes calcium hydroxyapatite (HA). ${ }^{4-6}$ Calcium phosphates have various other applications including acidity regulator, emulsifier, leavening agent, anticoagulant and moisture retaining agent, plant tissue sealant, and fertilizer.

The changes in physical and chemical properties, including crystallography and thermodynamic parameters in calcium phosphates such as due to ion substitution and phase 
transformations are well studied in the $20^{\text {th }}$ century ${ }^{1}$. However, it is unclear so far why certain forms of calcium phosphates are precipitated under specific $\mathrm{pH}$ of the solution, $\mathrm{Ca} / \mathrm{P}$ molar ratio, or precipitation method. Specifically, conditions of precipitation and ranges of phase transitions of metastable states of calcium phosphates are also not fully investigated. This gap in fundamental science has limited accurate behavier of calcium phosphates in various applications such as to medical and cosmetic applications and novel phosphate fertilizers for agricultural applications ${ }^{4}$. Therefore a detailed understanding of the mechanism of phase transformation during synthesis as well as during dissolution is needed,

In the $\mathrm{Ca}(\mathrm{OH})_{2}-\mathrm{H}_{3} \mathrm{PO}_{4}-\mathrm{H}_{2} \mathrm{O}$ system, the formation of eight individual calcium orthophosphates with a molar ratio of $\mathrm{Ca} / \mathrm{P}$ in the range from 0.5 to 1.67 are well known: $\mathrm{Ca}\left(\mathrm{H}_{2} \mathrm{PO}_{4}\right)_{2} \cdot \mathrm{H}_{2} \mathrm{O}, \mathrm{Ca}\left(\mathrm{H}_{2} \mathrm{PO}_{4}\right)_{2}, \mathrm{CaHPO}_{4} \cdot 2 \mathrm{H}_{2} \mathrm{O}$ (DCPD), $\mathrm{CaHPO}_{4}(\mathrm{DCPA}), \alpha-\mathrm{Ca}_{3}\left(\mathrm{PO}_{4}\right)_{2}, \beta-$ $\mathrm{Ca}_{3}\left(\mathrm{PO}_{4}\right)_{2}, \mathrm{Ca} 8\left(\mathrm{HPO}_{4}\right)_{2}\left(\mathrm{PO}_{4}\right)_{4} \cdot 5 \mathrm{H}_{2} \mathrm{O}$ and $\mathrm{HA}$. Moreover, variable composition of phosphates generates other group: amorphous calcium phosphate $\mathrm{Ca}_{x} \mathrm{H}_{\mathrm{y}}\left(\mathrm{PO}_{4}\right)_{\mathrm{z}} \mathrm{nH}_{2} \mathrm{O}(\mathrm{Ca} / \mathrm{P}=1,2-2,2)$ and Ca-deficient hydroxyapatite $\mathrm{Ca}_{10-\mathrm{x}}\left(\mathrm{HPO}_{4}\right)_{\mathrm{x}}\left(\mathrm{PO}_{4}\right)_{6-\mathrm{x}}(\mathrm{OH})_{2-\mathrm{x}}(\mathrm{Ca} / \mathrm{P}=1.50-1.67)^{7,8}$. A separate group of calcium orthophosphates are formed from ion-substitution: fluoroapatites $\mathrm{Ca}_{10}\left(\mathrm{PO}_{4}\right)_{6} \mathrm{~F}_{2}$ and $\mathrm{Ca}_{10}\left(\mathrm{PO}_{4}\right)_{6} \mathrm{~F}(\mathrm{OH})$, carbonate-containing apatites, apatites with the addition of cations of various metals ${ }^{4,9,10}$. Among these groups, two-, three- and even multi-phase calcium orthophosphates, in which the individual components cannot be separated from each other, are known ${ }^{1}$. Transformational or dry synthesis routes at high temperature generate another group: tetracalcium phosphate $\mathrm{Ca}_{4}\left(\mathrm{PO}_{4}\right)_{2} \mathrm{O}$, oxyapatite $\mathrm{Ca}_{10}\left(\mathrm{PO}_{4}\right)_{6} \mathrm{O}$, tricalcium phosphate $\mathrm{Ca}_{3}\left(\mathrm{PO}_{4}\right)_{2}$. For example, tricalcium phosphate is formed by heat treatment above $800^{\circ} \mathrm{C}$ from calcium and phosphorus precursors at a $\mathrm{Ca} / \mathrm{P}$ ratio of 1.5 . This phosphate is stable at room temperature but hydrolyzed in an aqueous solution, which indicates its metastable nature.

As outlined above, the possibility of the formation of metastable phases and additional phase transformations significantly complicates the choice of optimal conditions for the synthesis of calcium orthophosphates ${ }^{8,11,12}$. The complexity of the calcium orthophosphates precipitation is well illustrated by Ferreira et al ${ }^{13}$ by highlighting the equimolar $\mathrm{Ca} / \mathrm{P}$ ratio of $\mathrm{Ca}(\mathrm{OH})_{2}$ and phosphoric acid forms DCPD and five stages of intermediate stages before the formation of hydroxyapatite (HA). According to Briak-Ben ${ }^{14}$, hydroxyapatite precipitation, when calcium salts and phosphate ions are mixed even at a strict stoichiometric $\mathrm{Ca} / \mathrm{P}$ ratio of 1.67 , occurs due to the formation of amorphous or Ca-deficient calcium phosphate. It should also be noted that the chemical composition of the hydroxyapatite surface does not 
necessarily coincide with its unit cell composition ${ }^{15}$. This discrepancy could be explained by the processes of hydrolysis and the metastable nature of the material. These lines of evidence from past studies allude that processes of chemical precipitation of calcium orthophosphates, specially metatable and intermediate phases, is by far from fully understood. In this communication, the phase transformations of metastable states calcium orthophosphates are studied. For the first time, we show that the kinetics of the reaction is controlled by distinct differences in activation energies, which form different metastable phases and limit phase transformations.

\section{Materials and methods}

Various calcium phosphate materials were synthesized at different conditions. In all cases, 1.0 M solutions of $\mathrm{CaCl}_{2}$ and $\mathrm{H}_{3} \mathrm{PO}_{4}$ of chemically pure or reagent grade (Reachim) were used as precursors of the synthesis. The calcium phosphate precipitation was performed by varying the $\mathrm{pH}$ of the solutions in the range of 3 to 11 and the molar ratio of $\mathrm{Ca} / \mathrm{P} 0.5$ to 1.67. $500 \mathrm{~mL}$ of distilled water was placed in the reaction flask and the $\mathrm{pH}$ was adjusted to the target value using solutions of hydrochloric acid or ammonia. The solutions of $\mathrm{CaCl}_{2}$ and $\mathrm{H}_{3} \mathrm{PO}_{4}$ prepared with a given ratio of $\mathrm{Ca} / \mathrm{P}$. The solution was continuously stirred using a blade stirrer at a speed of $300 \mathrm{rpm}$ and $1.0 \mathrm{M}$ ammonia solution was simultaneously added to the solution using peristaltic Micro-Dosers at a flow rate of $0.05-1 \mathrm{~mL} / \mathrm{min}$. The flow rate of the reagent solutions was selected based on the stoichiometry of precipitation reactions and based on pilot experiments so that the $\mathrm{pH}$ of the solution remained at a given level with an accuracy of $\pm 0.1 \mathrm{pH}$ using a pH meter Adwa AD8000 (accuracy of $\pm 0.05 \mathrm{pH}$ units) throughout the precipitation process. After precipitation, the products were kept under stirring in the reactor for additional $6 \mathrm{~h}$. This process of "maturation" contributes to the crystallization of precipitates, and allows proper identification by powdered X-ray diffraction. The resulting suspensions were filtered under vacuum, washed with small portions of cold distilled water and then freeze dried to constant weight before analysis.

To determine the $\mathrm{Ca} / \mathrm{P}$ molar ratio, synthesized precipitates were dried to constant weight and homogenized by grinding in an agate mortar. A weighed quantity of the precipitates were dissolved in a concentrated $\mathrm{HCl}$ in volumetric flasks. Concentration of orthophosphate was performed in separate aliquots by using colorimetric method in which reduction reaction of heteropolyacid formed by the reaction of orthophosphate ions with ammonium molybdate in acidic condition. Concentration of calcium ion was determined by 
inductively coupled plasma optical emission spectroscopy (ICP-OES) using an Optima 8000 spectrometer (PerkinElmer, Norwalk, CT, USA).

$\mathrm{X}$-ray phase analysis was performed using a DRON-2 diffractometer in monochromatic Co- $\mathrm{K}_{\alpha 1}$ radiation. To identify the phase composition from the PCPDFWIN database, the diffraction patterns were recalculated on $\mathrm{Cu}-\mathrm{K}_{\alpha 1}$ radiation. The degree of crystallinity $\left(X_{C}\right)$, corresponding to the fraction of the crystalline phase in the test volume, was evaluated by the equation:

$$
B_{h k l l} \sqrt[a]{X_{C}}=K_{v}
$$

where $K$ is a constant equal to 0.24 , used for different hydroxyapatite in powder diffraction, and $B_{h k l}$ is the width (hkl) of the reflex at its half-height ${ }^{16}$.

The solubility of calcium phosphate precipitates was calculated by using the formula for the solubility product, as:

$$
K_{S}=\left[\mathrm{Ca}^{2+}\right]^{10}\left[P \mathrm{P}_{4}^{3-}\right]^{6}\left[O H^{-}\right]^{2}=\left(10 \beta_{0} S\right)^{10}\left(6 \alpha_{3} S\right)^{6}\left(S+C_{O H}\right)^{2},
$$

where $S$ is the solubility (mol/l), $\alpha_{i}$ and $\beta_{i}$ are the proportions of anions and cations of the precipitate. Similarly, $K_{1}, K_{2}$, are $K_{3}$ are acid dissociation constants and $K_{1}{ }^{*}$ and $K_{2}{ }^{*}$ are stability constants of the cation hydroxy complexes. The expression for $\alpha_{3}$ and $\beta_{0}$ are as follows:

$$
\begin{gathered}
\alpha_{3}=\frac{K_{1} K_{2} K_{3}}{\left[\mathrm{H}^{+}\right]^{3}+\left[\mathrm{H}^{+}\right]^{2} K_{1}+\left[\mathrm{H}^{+}\right] K_{1} K_{2}+K_{1} K_{2} K_{3}}, \\
\beta_{0}=\frac{1}{1+\left[\mathrm{OH}^{-}\right] K_{1}^{*}+\left[\mathrm{OH}^{-}\right]^{2} K_{1}^{*} K_{2}^{*}} .
\end{gathered}
$$

The following values of solubility products were used in the calculations (negative logarithms of their values are indicated in brackets): $\mathrm{Ca}\left(\mathrm{H}_{2} \mathrm{PO}_{4}\right)_{2} 2 \mathrm{H}_{2} \mathrm{O}$ (1.14), DCPD (6.59), DCPA (6.90), amorphous calcium phosphates $\mathrm{Cax}_{\mathrm{x}} \mathrm{H}_{\mathrm{y}}\left(\mathrm{PO}_{4}\right)_{\mathrm{z}} \cdot \mathrm{nH}_{2} \mathrm{O}$ with $\mathrm{Ca} / \mathrm{P}=1.2-2.2$ (2633), $\alpha$ - and $\beta-\mathrm{Ca}_{3}\left(\mathrm{PO}_{4}\right)_{2}(40)$, Ca-deficient hydroxyapatites $\mathrm{Ca}_{10-\mathrm{x}}\left(\mathrm{HPO}_{4}\right)_{\mathrm{x}}\left(\mathrm{PO}_{4}\right)_{6-\mathrm{x}}(\mathrm{OH})_{2-\mathrm{x}}$ with $\mathrm{Ca} / \mathrm{P}=1.5-1.67(114-155), \mathrm{Ca}\left(\mathrm{HPO}_{4}\right)_{2}\left(\mathrm{PO}_{4}\right)_{4}(96.6), \mathrm{HA}(155){ }^{17}$.

\section{Results and discussion}

The summary of experimental conditions and compositions of the synthesized products are reported in Table 1. At the early stage of precipitation, the maturation of precipitates at lower $\mathrm{pH}$ and at $15-30^{\circ} \mathrm{C}$ lead to the formation of well crystalline forms of 
DCPD and DCPA. The degree of their crystallinity varies in the range of $17-35 \%$ and can be considered as a result of chemical precipitation. With a decrease in $\mathrm{pH}$ of the reactant mixture, a progressive decrease in the degree of crystallinity of the precipitates was found.

In acidic solutions at room temperature, crystal hydrate of DCPD (PCPDFWIN No. 72-0713) is formed. However, its anhydrous form, DCPA (PCPDFWIN No. 77-0128), is crystallized directly in the solution during precipitation at $50^{\circ} \mathrm{C}$ and above. The conversion of DCPD to DCPA has been reported earlier ${ }^{17}$. This process proceeds at a noticeable rate already at a temperature of $37^{\circ} \mathrm{C}$. The dehydration of DCPD is reported to occur at temperature above $80^{\circ} \mathrm{C}{ }^{1}$, which, however, has been found at a much lower temperature in this study.

Fig. 1 shows the diffraction patterns of calcium orthophosphates synthesized at temperatures range from 15 to $90^{\circ} \mathrm{C}$. The change in diffraction patterns of precipitates maturated at $\geq 50^{\circ} \mathrm{C}$ indicates a significant rearrangement of the crystal lattice in DCPD. In fact, the conversion of DCPD to DCPA is caused by the rearrangement of the crystal lattice. According to reference data, DCPD has a monoclinic crystal lattice with the parameters $a=$ 5.812, $b=15.18$, and $c=6.239$, while DCPA has triclinic with $a=6.900, b=6.650$, and $c=$ 7.000 .

Diffraction patterns in Fig. 1 from the PCPDFWIN reference database show an apparent low angle shift by 0.3-0.45 degrees of all diffraction peaks relative to their reference values. Additional studies have shown that the magnitude of shift of peaks decreases with increasing time of maturation of precipitates in the supernatant ${ }^{17}$. It should be noted that this effect is only observed in precipitates that have not been thermally treatment after precipitation, such as reference calcium phosphates presented in the PCPDFWIN. These differences are better explained based on the solid-state chemistry principle that lattice strain decreases with an increase in temperature or time of maturation. During thermal treatment of crystalline or partially crystalline precipitate in hydrated media, crystallites continue to grow, which in turn reduces the lattice strain of the crystal structure and consequent decrease in interplanar spacing. Contrarily to acidic synthesis, the precipitation in an alkaline medium showed stable amorphous precipitate, which practically does not crystallize at $15-30^{\circ} \mathrm{C}$, even if they are kept in solution for several days (Fig. SI 1-3). They did not show any shift in peak position on the diffraction patterns. 
Given that the structure of the precipitate is determined by the precipitation rate $(r)$, which is a function of the degree of supersaturation of the product in the solution, the relationship could be written as follows:

$$
r=k\left(\Omega^{1 / 3}-1\right)^{n},
$$

where $k$ is the rate constant, $n$ is the order of precipitation (as a rule of thumb, $n>10$ ), $\Omega$ is the degree of supersaturation (the ratio of the ion activities product in the supersaturated solution to the thermodynamic solubility product of the precipitate ${ }^{18}$. In acidic solutions, the degree of supersaturation of the reagent mixture is relatively small due to excess of protonated $\mathrm{H}_{2} \mathrm{PO}_{4}{ }^{-}$over $\mathrm{HPO}_{4}{ }^{2-}$ species. This reduces the growth rate of DCPD nuclei and thus creates the conditions for the formation of the most thermodynamically stable crystal lattice at given $\mathrm{pH}$. As the degree of supersaturation increases, the precipitation rate increases and the precipitate is formed in a less energetically favorable crystal lattice. With a further increase in $\mathrm{pH}$, the size of the DCPD particles decreases with the eventual formation of amorphous products in alkaline solutions.

As illustrated from data reported in Table 1, the phase compositions of calcium phosphate precipitates do not depend on the starting $\mathrm{Ca} / \mathrm{P}$ molar ratio. For example, mixing aqueous solutions of reagents with molar ratios of $\mathrm{Ca} / \mathrm{P}=0.5$ and 1.5 at $\mathrm{pH}=3-4$ and $\mathrm{pH}=6$, formed the solid precipitate of $\mathrm{DCPD}$ with $\mathrm{Ca} / \mathrm{P}$ ratio of $1.00 \pm 0.05$. Similarly, mixing aqueous reagents with a molar ratio of $\mathrm{Ca} / \mathrm{P}=1.0$ and 1.67 at $\mathrm{pH} 8$, amorphous precipitates with a molar ratio of $\mathrm{Ca} / \mathrm{P}$ ca. 1.50-1.61 were obtained. An increase of the maturation temperature to $50^{\circ} \mathrm{C}$ improved the degree of crystallinity of the precipitates and formed Cadeficient hydroxyapatite (Fig. SI 4). A further increase in synthesis $\mathrm{pH}$ to 11 with an initial molar ratio of reagents of $\mathrm{Ca} / \mathrm{P}=0.5$, an amorphous precipitate was formed with $\mathrm{Ca} / \mathrm{P}=$ $1.67 \pm 0.05$. However, PXRD diffraction peaks confirmed the presence of some long-range atomic order of hydroxyapatite (Fig. SI 3).

The role of differences in the $\mathrm{Ca} / \mathrm{P}$ ratios in the reagent mixture in the products have been repeatedly noted in the literature. For example, Zyman at al. ${ }^{12}$ prepared phosphate products with $\mathrm{Ca} / \mathrm{P}$ ratio 1.5 at $\mathrm{pH}=10$ from a reagent mixture with an initial ratio of $\mathrm{Ca} / \mathrm{P}=$ 1: 1. They explained this discrepancy by the hydrolysis of the fraction of DCPD during washing of precipitates after synthesis. These results indicate that when mixing solutions of calcium and orthophosphate salts with the ratio $\mathrm{Ca} / \mathrm{P}=1$, the formation of hydroxyapatite with $\mathrm{Ca} / \mathrm{P}$ ratio $=1.5$ is possible. In our study, mixing solutions with $\mathrm{Ca} / \mathrm{P}$ ratio as low as 0.5 in alkaline solutions formed an amorphous precipitate with a ratio of $\mathrm{Ca} / \mathrm{P}=1.67 \pm 0.05$ (Table 
1). This amorphous phase is a precursor for the crystallization of apatite, although the rate of crystal growth is very low at $20^{\circ} \mathrm{C}$. Thus, in contrast to the $\mathrm{pH}$ of the reaction medium- a master variable, the molar $\mathrm{Ca} / \mathrm{P}$ ratio of initial reagents does not play a critical role in determining the final composition of calcium phosphate precipitates. The differences in $\mathrm{Ca} / \mathrm{P}$ ratio between the initial reagent mixture and resulted precipitate at the end of crystallization should be only induced by minor presence of $\mathrm{CaCO}_{3}$ from atmospheric air at the impurities level because the magnitude of coprecipitation of certain ions depends on their concentration in solution and the order of mixing of solutions of synthesis precursors. It is noteworthy to mention that even if $\mathrm{Ca} / \mathrm{P}$ ratio of initial reagents used for synthesis is equal to the stoichiometric hydroxyapatite (i.e., 1.667), non-stoichiometric precipitates, such as amorphous phosphates, are still formed as a side product. ${ }^{1}$.

The effect of $\mathrm{pH}$ on the composition of chemically pure calcium orthophosphate precipitates can be illustrated in a solubility isotherm (Fig. 2). As shown, the optimal pH for the synthesis of calcium phosphates can be chosen based on the need of solubility and stability of crystalline phases, which, however, depends on the precipitation method, synthesis temperature, and aging condition. According to thermodynamic calculation on phase precipitation, hydroxyapatite is the least soluble in the entire range of $\mathrm{pH}$ values from 0 to 14 (Fig. 2).

The variable range of solubility of precipitates are shown by shaded zones ( 4 and 7 in Fig. 2). The actual loci of these isotherms depend on chemical composition and the equilibrium constant $\left(\mathrm{K}_{\mathrm{sp}}\right)$ of the precipitate. A range of solubility isotherms of amorphous calcium phosphates $\mathrm{Ca}_{x} \mathrm{H}_{\mathrm{y}}\left(\mathrm{PO}_{4}\right)_{\mathrm{z}} \mathrm{nH}_{2} \mathrm{O}$ with a molar ratio of $\mathrm{Ca} / \mathrm{P}=1.2-2.2$ lie between curves 3 and 5 . At $\mathrm{pH}<6$, calcium phosphates are precipitated in crystalline form due to the relatively low concentration of $\mathrm{HPO}_{4}{ }^{2-}$ ions. Suitable time of maturation and temperature can promote their conversion into less soluble and more thermodynamically stable forms of calcium phosphates. The range of thermodynamic states of isotherms lies between curves 6 and 8 for Ca-deficient hydroxyapatites with a molar ratio of $\mathrm{Ca} / \mathrm{P}=1.5-1.67$. All of them are metastable in hydrated conditions, which means in the presence of excess calcium ions, they transforms into stoichiometric hydroxyapatite.

As shown in Fig. 2, the precipitates of DCPD and DCPA are metastable, which transform into more stable phosphates over time or increase in temperature. This conclusion was based on series of experimentation. Heating DCPA precipitates at $\mathrm{pH}=6$ in an autoclave at $250{ }^{\circ} \mathrm{C}$ for $6 \mathrm{~h}$ resulted in a mixture of anhydrous DCPA and hydroxyapatite HA. This 
partial transformation of DCPA is well explained by the kinetic inhibition of the reaction. The irreversibility of the phase transition from DCPD to DCPA was reported earlier ${ }^{17}$. However, other authors ${ }^{19}$ have shown that DCPA is fairly resistant to hydration and does not transform to DCPD at a temperature of $4-50{ }^{\circ} \mathrm{C}$ for as long as seven months. The solubility isotherms in Fig. 2 explain these patterns well. The change of thermodynamic state from isotherm 6 to 8 is energetically favorable. However, activation energy could be a barrier to this transformation. It is obvious that an increase in temperature is required to overcome this barrier, which is confirmed by our experimental results and literature data. For example, Cadeficient hydroxyapatite can be obtained by simultaneous addition of calcium and phosphoric acid salts in the ratio $\mathrm{Ca} / \mathrm{P}=1.50-1.67$ in boiling water at $\mathrm{pH}=6.5-9.5$, followed by boiling the suspension for several hours. Similarly, stoichiometric hydroxyapatite can be synthesized at a temperature of $\sim 90^{\circ}$ at the ratio of $\mathrm{Ca} / \mathrm{P}=1.67$ and $\mathrm{pH}=9.5-12^{20}$.

Considering that the intensity of diffraction peaks is proportional to the planar density of all crystallites formed under specific crystallization conditions, activation energies (minimum energy required for growing the crystalline phase) are calculated. To a first approximation, the rate of transformation of the crystal lattice and the rate of conversion of certain interplanar distances are described by a kinetic equation of pseudo-first order:

$$
\frac{d I}{d t}= \pm k I
$$

or in integral form:

$\ln I=\ln I_{0} \pm k t$, where $k$ is the rate constant, $I$ is the current intensity of the diffraction pattern, which reflects the state transformation (i.e., transition from the metastable state to the next, second thermodynamically more stable state of precipitate in the process of maturation in the supernatant), $I 0$ is the intensity of diffraction peak at time $t=0$. The equations are expressed in \pm sign because the intensity of the reflection can both increase and decrease It is clear that at $\mathrm{t}=\mathrm{const}$ the logarithm applied to reflection peaks is proportional to rate constant of phase transition. Assuming that activation energy $\left(E_{a}\right)$ does not depend on temperature the calculated values of logarithm of intensity from reflections provide a beneficial tool that allows for comparison between different states of phase transition.

After integrating the Arrhenius equation in a narrow temperature range $T_{1}$ and $T_{2}$ (assuming that the activation energy $\left(E_{a}\right)$ does not depend on the temperature), the revised expression of the equation: 


$$
\ln \frac{k_{2}}{k_{1}}=\frac{E_{a}}{R}\left(\frac{1}{T_{1}}-\frac{1}{T_{2}}\right) .
$$

The above equation can be expressed using the logarithms of the peak intensities of the diffraction patterns instead of the rate constants for precipitates that are present in the supernatant for the same time but at different temperatures. Given that peak intensity can increase or decrease, the expression above can be expressed in a modulus form:

$$
\left|\ln \left(\frac{\ln I_{2}}{\ln I_{1}}\right)\right|=\frac{E_{a}}{R}\left(\frac{1}{T_{1}}-\frac{1}{T_{2}}\right) .
$$

This formula allows to calculate the activation energies at any given value of $2 \theta$ diffraction patterns of precipitates that undergo phase transition after precipitation. The results of calculated values of Ea for diffractograms in Fig. 1 are reported in Fig 3. In present calculations the ranges of diffractograms with typical reflections of DCPD and DCPA were used whereas areas with no diffraction peaks were excluded due to significant contribution of error in estimation of Ea and thus irrelevant in representation of crystalline lattice structures of the studied here phases.

Based on the results obtained from calculations using equations above and presented in Fig. 3, we conclude that the change of each interplanar distance in the crystal lattice is characterized by its activation energy. The appearance and disappearance of certain peaks on the diffraction pattern require overcoming a specific activation energy barrier. Fig. 3 show the upper limit of the activation energy, which is a more appropriate estimate of the crystallization process than the average values. Crystallization (growth of long-range atomic order in particles due to diffusion of ions from solution), recrystallization (growth of longrange atomic order in particles due to diffusion of ions within the solid phase of particles), or phase transformation are interconnected and complementary and cannot exist, in most cases, without each other. Fig. 3 show a notable difference in activation energies for the recrystallization process, which in turn, will determine the overall rate of this reaction. Thus, the transformation of the interplanar distances in the crystal lattice with the largest $E a$ value will be the limiting factor for all reactions.

The maximum activation energy calculated using the above relationship for DCPD recrystallization $10.2 \mathrm{~kJ} / \mathrm{mol}$. Similarly, the energy for the recrystallization of anhydrous DCPA - $13.1 \mathrm{~kJ} / \mathrm{mol}$, transition DCPD to DCPA phase - $36.7 \mathrm{~kJ} / \mathrm{mol}$, and for recrystallization to $\mathrm{HA}-5.2 \mathrm{~kJ} / \mathrm{mol}$. These results suggest that the reconstruction of the crystal lattice requires much more energy than the crystal growth or hydrolysis of certain 
faces of the crystal or crystallite of the polycrystalline material. The kinetics of the DCPD crystallization in supersaturated solutions at $\mathrm{pH}=5.4-6.2$ was calculated by measuring the concentrations of calcium ions and phosphates at temperatures of 15,25 , and $37^{\circ} \mathrm{C}^{21}$. These authors found that the activation energy of DCPD crystals growth is $44.0 \mathrm{~kJ} / \mathrm{mol}$, which indicates the process of crystallization was in the kinetic mode. Similarly, activation energy of the dissolution of DCPD crystals in unsaturated solutions at $\mathrm{pH}=5.0-5.6$ was $15.9 \mathrm{~kJ} / \mathrm{mol}$ 22. These authors concluded that the dissolution rate of DCPD is controlled by the site of calcium ions and diffusion rate of phosphates from crystal surface.

It should be noted that in our experiments, both the precipitation and maturation of calcium phosphates were carried out under continuous stirring with a blade stirrer at a speed of $\sim 300 \mathrm{rpm}$. Herewith, the precipitates were present in saturated solution, which means the content of the precipitate is determined by the solubility. The growth of crystals under such conditions is possible only due to two steps: dissolution of nano- or microparticles and crystallization of larger particles, Ostwald Ripening. It is obvious that the total crystal growth rate under such conditions should be controlled at the lowest (limiting) rate. On the other hand, increasing the degree of crystallinity (long-range atomic order) can be considered as a process of recrystallization, when, for example, the amorphous portion of the precipitate at the boundary with the crystallites gradually turns into a crystalline state, thus extending the length of atomic order. This process can take place not only on the surface, but also in the volume of the solid phase, where the diffusion processes are not associated with gradients of concentrations of calcium and phosphates in solution. It is more likely that in both processes: Ostwald ripening on the surface and recrystallization in the volume of precipitate particles occur side by side. Comparable and low activation energies $(10.8 \mathrm{~kJ} / \mathrm{mol}$ for DCPD and 11.2 $\mathrm{kJ} / \mathrm{mol}$ for DCPA) suggest that the limiting reaction is likely the diffusion of ions. For the phase transition of DCPD to DCPA, the activation energy of $36.7 \mathrm{~kJ} / \mathrm{mol}$ indicates the kinetic nature of reaction, which induces a conversion of the monoclinic crystal lattice of DCPD into a triclinic lattice of anhydrous DCPA. Overall, these results conclude that a caution needed to compare the literature data ${ }^{21,22}$ with current results on activation energy. To make a distinction, we used the term "recrystallization", to represent the growth of crystallites of polycrystalline material at the expense of others.

\section{Conclusion}

The study on kinetics of crystallization and transformation of metastable calcium orthophosphates under different synthesis conditions $(\mathrm{pH}$, temperature, and molar ratio $\mathrm{Ca} / \mathrm{P})$, 
specifically the phase composition and degree of crystallinity, generated insightful outcomes. In acidic solutions $\left(\mathrm{pH}=3-6, \mathrm{t}=15-90^{\circ} \mathrm{C}\right), \mathrm{DCPD}$ and DCPA precipitates are formed in the crystalline state ( degree of crystallinity $=17-35 \%)$. In alkaline solutions $(\mathrm{pH}=8-10, \mathrm{t}=15$ $30^{\circ} \mathrm{C}$ ) calcium orthophosphates are precipitated only in amorphous state. This is due to a high degree of supersaturation of solutions, and consequently, the higher precipitation rate compared to that in acidic media. A shift of all diffraction peaks of DCPD and DCPA by 0.3$0.452 \theta$ degrees relative to the reference data was found to be related to time for maturation. Our data shows that the magnitude of the shift decreases with the increase in time of maturation of precipitates in the supernatant, analogous to commonly described solid state chemistry principle in which decrease of lattice strain as a result of growth of long-range atomic order.

We conclude that, unlike $\mathrm{pH}$ as the master variable of the form, the initial molar ratio of $\mathrm{Ca} / \mathrm{P}$ reagents in the media has a minor role in determining the fundamental composition of calcium phosphate precipitates. Differences should be expected only at level of minor impurities, because the magnitude of coprecipitation of certain ions depends on their concentration in solution and the order of mixing of solutions of synthesis precursors.

The effect of $\mathrm{pH}$ on the composition of precipitates is illustrated by the solubility isotherms of known calcium orthophosphate phases. Based on this calculations, for the entire range of $\mathrm{pH}(0-14)$, hydroxyapatite is the least soluble phosphate. The solubility isotherms allowed to establish energetically possible phase transitions between metastable states of calcium phosphates with activation energy being a barrier of transition. An increase in temperature is often the factor to overcome this activation barrier. Since the intensity of diffraction peaks is proportional to planar density of given plane in the material, we proposed an equation to calculate the values of activation energy of phase transformation, for the first time, from X-ray diffraction patterns. The calculated activation energy for DCPD recrystallization is $10.2 \mathrm{~kJ} / \mathrm{mol}$, for recrystallization of anhydrous DCPA is - $13.1 \mathrm{~kJ} / \mathrm{mol}$, and phase transition of DCPD to DCPA is- $36.7 \mathrm{~kJ} / \mathrm{mol}$, and for recrystallization of hydroxyapatite $\mathrm{Ca}_{10}\left(\mathrm{PO}_{4}\right)_{6}(\mathrm{OH})_{2}$ to be $-5.2 \mathrm{~kJ} / \mathrm{mol}$. These results, overall, show that the physical model of calcium phosphate transformation where reconstruction of the crystal lattice requires more energy than that in the crystal growth or dissolution. 


\section{References}

1 Dorozhkin, S. V. Calcium orthophosphate-based bioceramics. Materials 6, 3840-3942 (2013).

2 Dorozhkin, S. V. Calcium orthophosphates (CaPO 4): occurrence and properties. Progress in biomaterials 5, 9-70 (2016).

3 Ślósarczyk, A., Czechowska, J., Cichoń, E. \& Zima, A. New Hybrid Bioactive Composites for Bone Substitution. Processes 8, 335 (2020).

4 Dorozhkin, S. V. Calcium orthophosphate-containing biocomposites and hybrid biomaterials for biomedical applications. Journal of functional biomaterials 6, 708$832(2015)$.

5 Lett, J. A. et al. Drug Leaching Properties of Vancomycin Loaded Mesoporous Hydroxyapatite as Bone Substitutes. Processes 7, 826 (2019).

6 Wang, L. \& Nancollas, G. H. Calcium orthophosphates: crystallization and dissolution. Chemical reviews 108, 4628-4669 (2008).

7 Brown, P. W. Phase Relationships in the Ternary System CaO- P2O5- $\mathrm{H} 2 \mathrm{O}$ at $25^{\circ}$ C. Journal of the American Ceramic Society 75, 17-22 (1992).

8 Martin, R. I. \& Brown, P. W. Phase equilibria among acid calcium phosphates. Journal of the American Ceramic Society 80, 1263-1266 (1997).

9 Lin, R. \& Ding, Y. A review on the synthesis and applications of mesostructured transition metal phosphates. Materials 6, 217-243 (2013).

10 Omelon, S. J. \& Grynpas, M. D. Relationships between polyphosphate chemistry, biochemistry and apatite biomineralization. Chemical reviews 108, 4694-4715 (2008).

11 McDowell, H., Gregory, T. \& Brown, W. Solubility of Ca5 $\{\mathrm{P} 04 \mathrm{hOH}$ in the System $\mathrm{Ca}\{\mathrm{OH}) 2-\mathrm{H} 3 \mathrm{P} 04-\mathrm{H} 20$ at 5, 15, 25, and $37 \mathrm{C}$. (1977).

12 Zyman, Z., Goncharenko, A., Khavroniuk, O. \& Rokhmistrov, D. Crystallization of metastable and stable phases from hydrolyzed by rinsing precipitated amorphous calcium phosphates with a given $\mathrm{Ca} / \mathrm{P}$ ratio of 1: 1. Journal of Crystal Growth 535, 125547 (2020).

13 Ferreira, A., Oliveira, C. \& Rocha, F. The different phases in the precipitation of dicalcium phosphate dihydrate. Journal of Crystal Growth 252, 599-611 (2003).

14 El Briak-BenAbdeslam, H., Ginebra, M., Vert, M. \& Boudeville, P. Wet or dry mechanochemical synthesis of calcium phosphates? Influence of the water content on DCPD-CaO reaction kinetics. Acta Biomaterialia 4, 378-386 (2008).

15 Nikolenko, N. \& Esajenko, E. Surface properties of synthetic calcium hydroxyapatite. Adsorption Science \& Technology 23, 543-553 (2005).

16 Bakan, F. A Systematic Study of the Effect of $\mathrm{pH}$ on the Initialization of Ca-deficient Hydroxyapatite to $\beta$-TCP Nanoparticles. Materials 12, 354 (2019).

17 Nikolenko, M. V., Vasylenko, K. V., Myrhorodska, V. D., Kostyniuk, A. \& Likozar, B. Synthesis of Calcium Orthophosphates by Chemical Precipitation in Aqueous Solutions: The Effect of the Acidity, Ca/P Molar Ratio, and Temperature on the Phase Composition and Solubility of Precipitates. Processes 8, 1009 (2020).

18 Nikolenko, M., Kostynyuk, A., Goutenoire, F. \& Kalashnikov, Y. V. Chemical precipitation of iron (III) molybdate+ molybdenum trioxide mixtures through continuous crystallization. Inorganic Materials 50, 1140-1145 (2014).

19 Miyazaki, T., Sivaprakasam, K., Tantry, J. \& Suryanarayanan, R. Physical characterization of dibasic calcium phosphate dihydrate and anhydrate. Journal of pharmaceutical sciences 98, 905-916 (2009).

20 Norton, J., Malik, K., Darr, J. \& Rehman, I. Recent developments in processing and surface modification of hydroxyapatite. Advances in Applied Ceramics 105, 113-139 (2006). 
21 Marshall, R. W. \& Nancollas, G. H. Kinetics of crystal growth of dicalcium phosphate dihydrate. The Journal of Physical Chemistry 73, 3838-3844 (1969).

22 Nancollas, G. H. \& Marshall, R. W. Kinetics of dissolution of dicalcium phosphate dihydrate crystals. Journal of dental research 50, 1268-1272 (1971).

\section{Acknowledgment}

This work was supported by a R\&D project 24/200490 (state registration number 0120U101971) of the Ukrainian State University of Chemical Technology . A part of this work was also supported from a research grant from the U.S. Department of Agriculture (NIFA award 2018-67021-27965).

\section{Author contributions}

M.N. designed the study and interpreted results; D.J. analyzed results and edited text; K.V. performed synthesis; Y.S. plotted figures, performed literature review and edited text. All authors contributed to the draf manuscript writing and approved the fnal version.

\section{Additional information}

Te authors declare no competing interests.

Correspondence and requests for materials should be addressed to M.N.

\section{Figure legends}

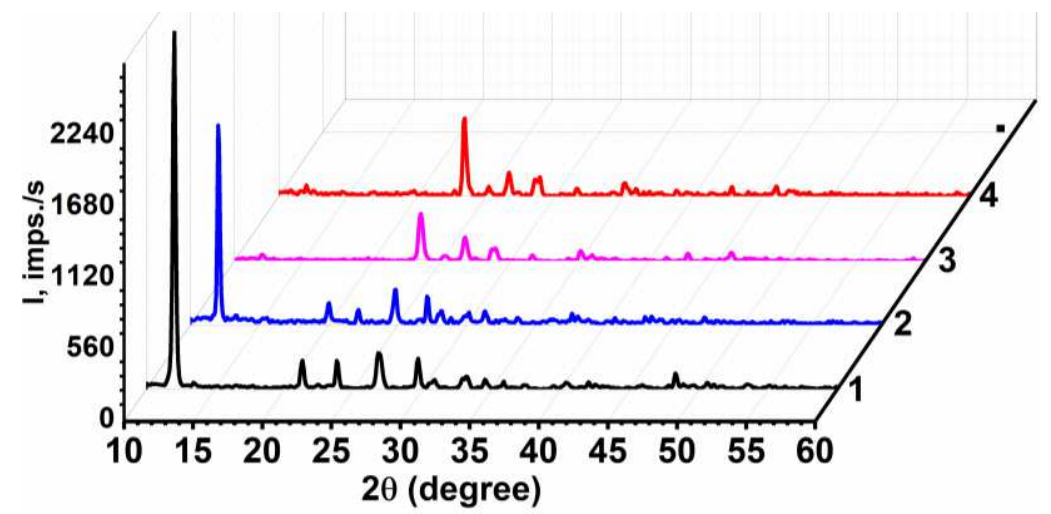

Fig. 1. Diffraction patterns of calcium orthophosphate synthesized at a constant $\mathrm{pH}$ (3.8) and initial $\mathrm{Ca} / \mathrm{P}$ ratio (0.5) but at four different temperatures: $15^{\circ} \mathrm{C}(1), 30^{\circ} \mathrm{C}(2), 50{ }^{\circ} \mathrm{C}(3)$, and $90{ }^{\circ} \mathrm{C}(4)$. The products were kept in the reaction medium for $6 \mathrm{~h}$ after precipitation. 


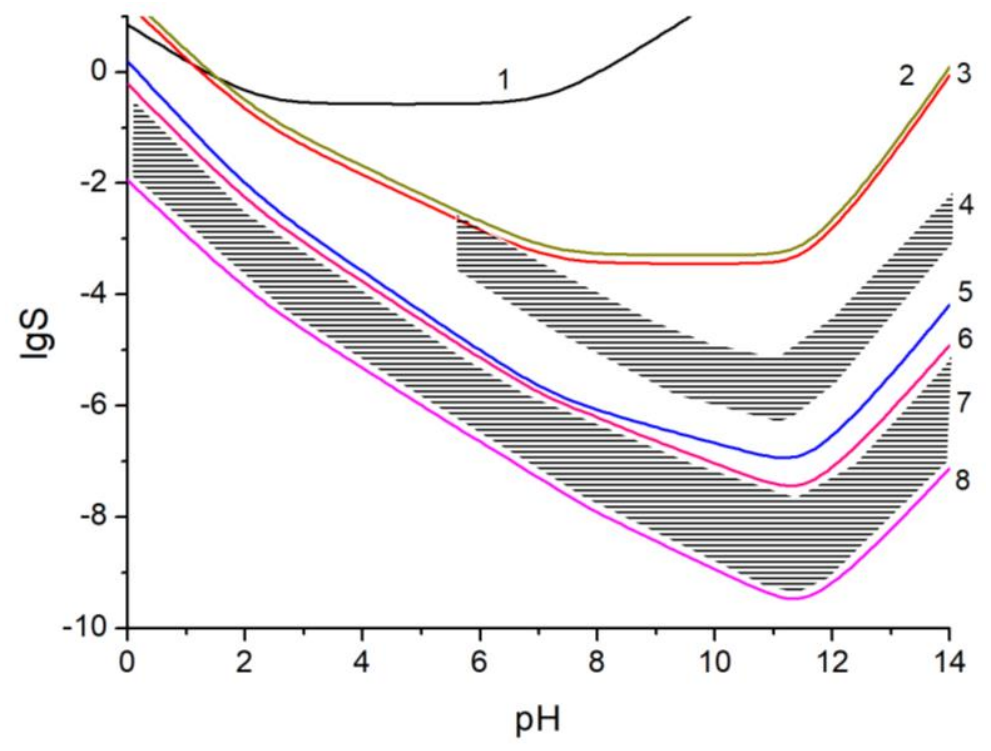

Fig. 2. Solubility isotherms of different calcium phosphates: 1) $\mathrm{Ca}\left(\mathrm{H}_{2} \mathrm{PO}_{4}\right)_{2} \cdot \mathrm{H}_{2} \mathrm{O}$, 2) DCPD, 3) DCPA, 4) amorphous precipitates $\mathrm{Ca}_{x} \mathrm{H}_{y}\left(\mathrm{PO}_{4}\right)_{z} \mathrm{nH}_{2} \mathrm{O}$, 5) $\left.\mathrm{Ca}_{8}\left(\mathrm{HPO}_{4}\right)_{2}\left(\mathrm{PO}_{4}\right)_{4} \cdot 5 \mathrm{H}_{2} \mathrm{O}, 6\right)$ $\left.\mathrm{Ca} 9\left(\mathrm{HPO}_{4}\right)\left(\mathrm{PO}_{4}\right)_{5}(\mathrm{OH}), 7\right) \mathrm{Ca}$-deficient (non-stoichiometric) hydroxyapatites $\mathrm{Ca}_{10}$ ${ }_{x}\left(\mathrm{HPO}_{4}\right)_{x}\left(\mathrm{PO}_{4}\right)_{6-\mathrm{x}}(\mathrm{OH})_{2-\mathrm{x}}$, and 8) stoichiometric hydroxyapatite HA.

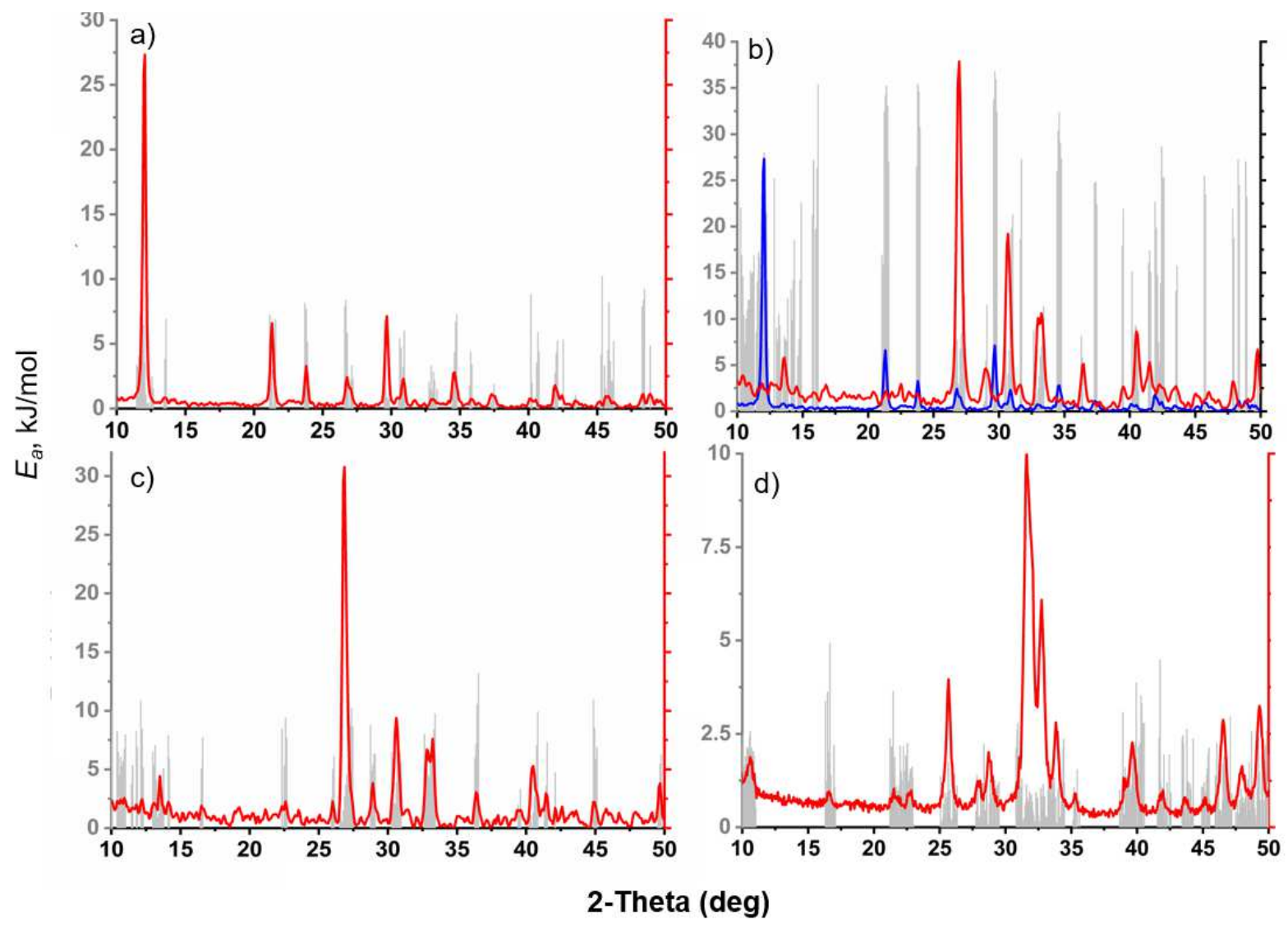


Fig. 3. PXRD diffractogram of pure DCPA (red) and DCPD ((blue) and calculation based on activation energies bars (grey). a) 14 and $30^{\circ} \mathrm{C}$, b) 30 and $50^{\circ} \mathrm{C}$, c) 50 and $90^{\circ} \mathrm{C}$ and d) at $50^{\circ} \mathrm{C}$.

Table

Table.1. Synthesis conditions, phase composition, and degree of crystallinity $\left(X_{c}\right)$ of calcium orthophosphate precipitates.

\begin{tabular}{cccllc}
\hline $\begin{array}{c}\mathbf{p H} \text { of the } \\
\text { precipitation }\end{array}$ & $\begin{array}{c}\mathbf{C a} / \mathbf{P} \text { in } \\
\text { solution }\end{array}$ & $\mathbf{T},{ }^{\circ} \mathbf{C}$ & $\begin{array}{c}\text { Phase composition of the } \\
\text { precipitate }\end{array}$ & $\begin{array}{c}\mathbf{C a} / \mathbf{P} \text { in } \\
\text { precipitate }\end{array}$ & $X_{C}, \boldsymbol{\%}$ \\
\hline 3.0 & 0.5 & 20 & DCPD & $1.00 \pm 0.05$ & 35 \\
3.8 & 0.5 & 15 & DCPD & $1.00 \pm 0.05$ & 17 \\
& & 30 & DCPD & $1.00 \pm 0.05$ & 17 \\
& & 50 & DCPA & $1.00 \pm 0.05$ & 18 \\
& & 90 & DCPA & $1.00 \pm 0.05$ & 32 \\
6.0 & 1.5 & 20 & DCPD & $1.00 \pm 0.05$ & 12 \\
8.0 & 1.0 & 15 & Amorphous precipitate & $1.50 \pm 0.05$ & 0 \\
& & 30 & Amorphous precipitate & $1.51 \pm 0.05$ & 0 \\
& & 50 & Ca-deficient hydroxyapatite & $1.55 \pm 0.05$ & 3 \\
8.0 & 1.67 & 15 & Amorphous precipitate & $1.53 \pm 0.05$ & 0 \\
& & 30 & Amorphous precipitate & $1.59 \pm 0.05$ & 0 \\
& & 50 & Ca-deficient hydroxyapatite & $1.61 \pm 0.05$ & 9 \\
11.0 & 0.5 & 20 & Amorphous precipitate & $1.67 \pm 0.05$ & 0
\end{tabular}




\section{Supplementary Files}

This is a list of supplementary files associated with this preprint. Click to download.

- SupportinginformationMay172021formated.docx 